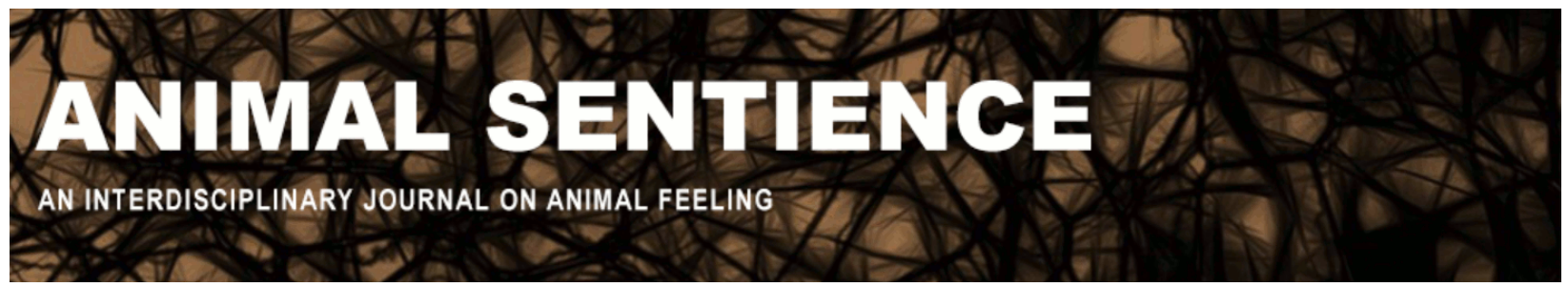

Brennan, Ozy (2019) Complexity of wild ruminants. Animal Sentience 25(38) DOI: 10.51291/2377-7478.1492

Date of submission: 2019-06-12

Date of acceptance: 2019-06-22

(c) (i)




\title{
Complexity of wild ruminants
}

\author{
Commentary on Marino \& Merskin on Sheep Complexity
}

\section{Ozy Brennan}

\begin{abstract}
Marino \& Merskin discuss ways that popular culture winds up depicting sheep as meek and unintelligent rather than as the complex, social species they are. I extend their analysis to apply to wild ruminants, particularly deer.
\end{abstract}

Ozy Brennan is an independent researcher focusing on effective animal activism. They previously worked for Wild Animal Suffering Research.

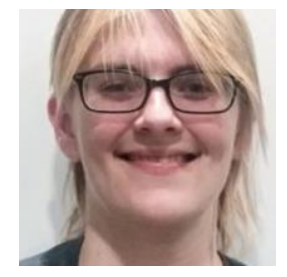

Human portrayals of nonhuman animals - both domestic and wild - are often inaccurate in ways that cause us to ignore their suffering. Marino and Merskin (2019) review the evidence for social complexity, personality, emotions, and high cognitive abilities among sheep. Contrary to their depiction in popular culture as docile, easily led, and rather stupid, sheep are intelligent and social animals. Just as the popular depiction of sheep does not represent their actual capacities, popular-culture depictions of wild ruminants, such as deer, do not accurately convey their abilities and experiences.

The cognitive abilities of deer have been understudied, and the studies that exist often focus primarily on hunting. However, the evidence is suggestive that deer may have quite complex cognitive abilities. Red deer are capable of distinguishing between the roars of their current harem-holder stag and those of neighboring stags (Reby et al., 2001). White-tailed deer assess the risk of predation in their environment, make tradeoffs between various options, and modify their behavior to reduce their risk of predation to an acceptable level (Ozoga, 1995). Over time, black-tailed deer learn how to forage for food more efficiently in a particular location (Gillingham and Bunnel, 1989). Fallow deer have personality traits such as boldness (Bergvall et al., 2011) and willingness to engage in fighting (Jennings, Hayden, and Gammel, 2013).

Marino and Merskin (2019) discuss one of the most important ways that the experiences of farmed animals are misrepresented: the idea that they have few cognitive capacities and are not worthy of moral concern. Wild animals are misrepresented in this way. But there's another, even more important way in which they are misrepresented: their experiences are idealized and shown to be unrealistically blissful.

Even many humans who care about nonhuman animals are unaware of the suffering endured by many wild animals. Many humans live in urban or suburban environments; their knowledge of wild animals comes mostly from non-representative sources such as fiction or 
wildlife documentaries. Our popular understanding of nature often underrepresents uncharismatic animals such as prey, small animals, and invertebrates, who may be particularly likely to suffer. Many of the animals who experience the most pain over their short lives die young; we think of the noble broad-antlered stag, but not of the many children he has fathered that do not survive their first year.

Popular children's film Bambi vividly depicts the fear of human hunters that shapes the lives of so many deer (see for example Kilgo, Labisky, and Fritzen, 1998). But nature undisturbed by humans is shown as an idyllic world of interspecies friendships, play, and (as Bambi's friends call the spring desire for love) "twitterpation." Bambi's life is undisturbed by nonhuman predators, starvation, parasites, chronic wasting disease, or bovine tuberculosis.

Like sheep, wild ruminants such as deer are intelligent individuals with unique personalities and complex cognitive capacities. Similarly to sheep, they are misrepresented in popular media. Many depictions of deer in popular culture fail to engage with them as individuals and instead treat them in a speciesist fashion as a source of food. Many others show their lives as pastoral utopias rather than engaging with the suffering that exists in nature.

\section{References}

Bergvall, U. A., Schäpers, A., Kjellander, P., \& Weiss, A. (2011). Personality and foraging decisions in fallow deer, Dama dama. Animal Behaviour, 81(1), 101-112.

Gillingham, P., \& Bunnell, F. L. (1989). Effects of learning on food selection and searching behaviour of deer. Canadian Journal of Zoology, 67, 24-32.

Jennings, D. J., Hayden, T. J., \& Gammell, M. P. (2013). Personality and predictability in fallow deer fighting behaviour: The relationship with mating success. Animal Behaviour, 86(5), 1041-1047.

Kilgo, J. C., Labisky, R. F., \& Fritzen, D. E. (1998). Influences of hunting on the behavior of whitetailed deer: Implications for conservation of the Florida panther. Conservation Biology, 12(6), 1359-1364.

Marino, L., \& Merskin, D. (2019). Intelligence, complexity, and individuality in sheep. Animal Sentience 25(1).

Ozoga, J. J. (1995). Whitetail Winter. Minocqua, WI: Willow Creek Press.

Reby, D., Hewison, M., Izquierdo, M., \& Pépin, D. (2001). Red deer (Cervus elaphus) hinds discriminate between the roars of their current harem-holder stag and those of neighbouring stags. Ethology, 107, 951-959. 